\title{
Ureteral realignment with combined access as a treatment of complete ureteral transection
}

\author{
Jorge Panach-Navarrete, Marcos Antonio Lloret-Durà, María Medina-González, \\ José María Martínez-Jabaloyas
}

Department of Urology, University Clinic Hospital of Valencia. Facultat de Medicina i Odontologia, Universitat de València, Valencia (Spain).

\begin{abstract}
Summary Ureteral realignment using a ureteral stent can be an alternative treatment in cases of complete ureteral transection and may avoid the need for reconstructive surgery. The combined access can help the passage of the guidewire through the injured area and the threading of the urinary system of the patient. We present a case of a 38-year-old man with multiples abdominal surgeries, who underwent a complete ureteral section treated with ureteral realignment with combined access. The subsequent evolution was favourable, with resolution of the ureteral injury at the acute time, and without the presence of long-term obstruction. Although we must accept that the standard treatment of the complete ureteral transection is reconstruction and anastomosis, in cases such as the one prsented, with multiple abdominal surgeries and whenever it is technically feasible, ureteral realignment may be a treatment option.
\end{abstract}

KEY WORDS: Ureteral transection; Ureteral trauma; Endourology; Ureteral realignment.

Submitted 15 April 2019; Accepted 29 April 2019

\section{INTRODUCTION}

Within urogenital system injuries, those in the ureter are relatively infrequent, representing around $1-2.5 \%$ of urological traumas. The most frequent location is the distal third of the ureter (73\% of cases); and the most frequent cause is surgical iatrogenic damage $(75 \%)$, which can produce avulsion, perforation, ligature or burning (1). Along with gynecological surgery, distal ureter injuries happen most frequently in colorectal surgeries, with a reported incidence of unnoticed ureteral injury of between 0.11 and $0.24 \%$. The diagnosis of these complications should be one of suspicion, as there are no specific signs. This fact implies that, sometimes, ureteral injuries are diagnosed in a deferred manner, in the postoperative period of surgeries (2).

The clinical guidelines on urological trauma of the European Association of Urology and the American Association of Urology agree that small lesions or ureteral fistulas are subsidiary of conservative treatment with the use of a ureteral stent, a procedure that is safe and effective. On the other hand, larger lesions should be treated with surgical reconstruction followed by urinary diversion $(1,3)$. We present in this work a case of complete ureteral transection successfully treated by ureteral realignment.

\section{Case report}

A 38-year-old man with a history of perforated acute diverticulitis, having been treated at first with sigmodectomy and reconstruction of intestinal transit. In the postoperative period he presented with a leak of the intestinal anastomosis, requiring an emergency colostomy. During the postoperative period of the second surgery, he required emergency splenectomy for unnoticed splenic injury during the colostomy. At 12 months, during the scheduled colostomy closure, an inadvertent ureteral injury was produced. Due to the patient's paralytic ileus, a computed tomography (CT) scan was performed one week later, finding a contrast leak in the middle area of the distal ureter in the excretory phase (Figure 1) and a pelvic collection secondary to the leak. Percutaneous drainage of the collection and urgent double J stent placement was decided.

In the ascending pyelography, complete extravasation of contrast outside the urinary tract was found about $4 \mathrm{~cm}$ above the bladder. In addition, it was not possible to raise the guidewire through the ureter. Ureterorenoscopy with a 9.5F semirigid instrument $\left(\right.$ Storz $\left.^{\circledR}\right)$ was decided, checking for a disheveled area and complete solution of continuity of the ureter, without reaching the proximal end of the ureter with any guidewire. At that time, given the history of multiple abdominal surgeries, the most

\section{Figure 1.}

UroCT at the time of diagnosis of the ureteral injury. Contrast leakage from the left pelvic ureter.

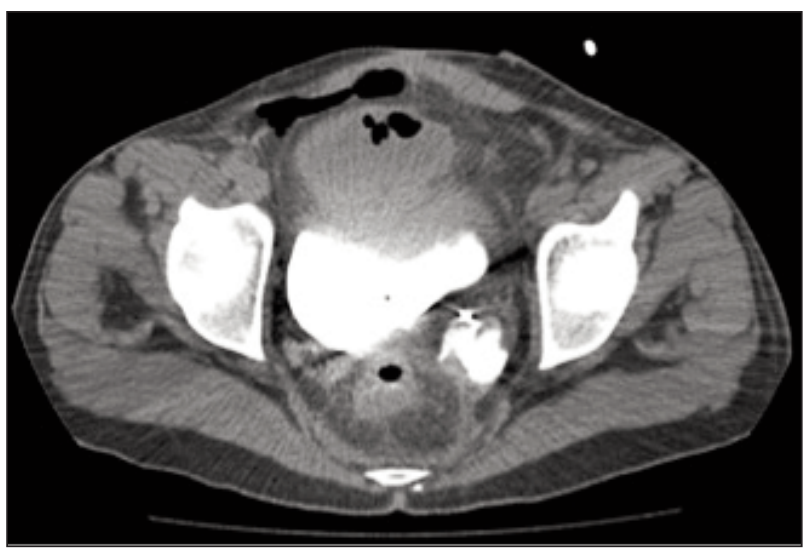

No conflict of interest declared. 


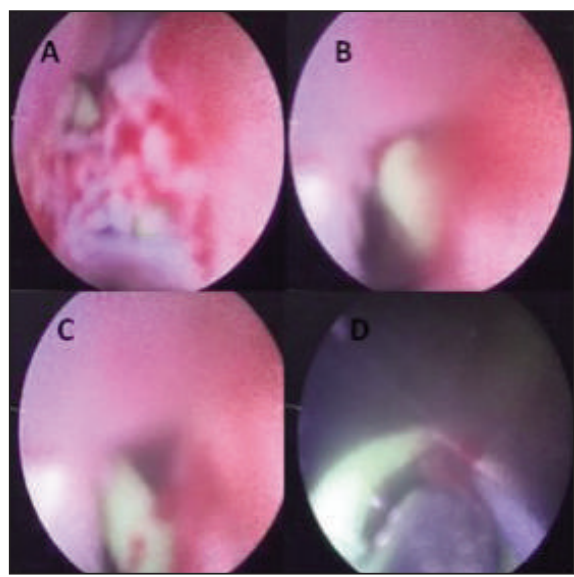

Figure 2.

Intraoperative images obtained during retrograde ureteroscopy.

recent a week before, ureteral realignment with combined access was decided. Then, after percutaneous puncture of the kidney, descending pyelography was performed, measuring a distance of about $2 \mathrm{~cm}$ between both ureteral ends. An anterograde guide coated with 0.035 "PTFE (Coloplast ${ }^{\circledR}$ )" was descended, outside of the urinary tract. Using the ureteroscope and with the help of a 0.035 "Sensor ${ }^{\circledR}$ guidewire (Boston Scientific $\left.{ }^{\circledR}\right)$ ", the area of the injury was reached, visualizing the PTFE guidewire outside of the tract (Figure 2). Arriving with the ureteroscope to the edge of the distal end, the PTFE guidewire was lowered to the bladder by means of foreign body forceps and then extracted through the urethra. With the patient threaded, a double J $6 \mathrm{~F}-26 \mathrm{~cm}$ Vortek $^{\circledR}$ stent (Coloplast) was placed retrogradely. In a control uro-CT scan performed a week later, no contrast leakage was found. The ureteral stent was removed after two months. A CT scan and renogram four months after the realignment showed minimal evident pathway in the left kidney and absence of obstruction, with a differential function for the affected kidney of 46\% (Figure 3).
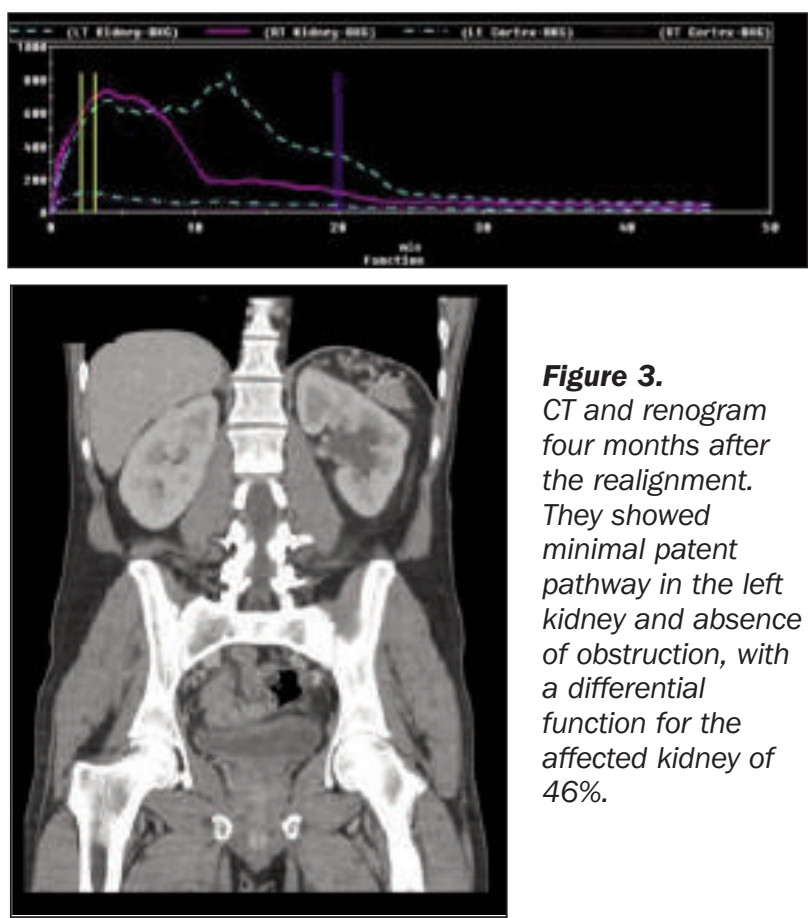

Figure 3.

CT and renogram four months after the realignment. They showed minimal patent pathway in the left kidney and absence of obstruction, with a differential function for the affected kidney of $46 \%$.

\section{Discussion}

The management of ureteral trauma should be initiated with the prevention of injury. The preoperative placement of a double J stent, the correct identification of the ureter and its proper dissection, are basic maneuvers for any surgery that develops in the proximity of the ureteral tract. In the case of injury, the ideal solution is immediate repair, although this action is not possible many times. That is why, sometimes, treatment must be individualized depending on the stability of the patient, the evolution time of the injury, its severity, or its exact location. Ureteral reconstruction with an ulterior temporary urinary diversion is the accepted treatment for major ureteral injuries $(1,3)$. In the case we present, it was decided to perform a realignment in spite of the intraoperative findings due to the patient's background. This procedure has been previously described by different authors in the context of a complete ureteral transection, with different approaches, number of stents used and maintenance period. Wang et al. used a retrograde approach, placing two stents for four months, and resolving the urine leak without long-term complications. In this case, the authors highlighted the difficulty of finding the proximal end under direct vision by retrograde ureteroscopy, solved with the combined approach that we carried out (4). On the other hand, Liu et al. reported eight cases of complete transection, treating them with combined access through flexible anterograde and rigid retrograde ureteroscope. This group placed three $5 \mathrm{Ch}$ stents, solving the ureteral discontinuity in all cases, but with the development of stenosis in three of the eight cases (5). As far as we know, this work is the third one that describes this technique. Although we must accept that the treatment of the complete ureteral transection is reconstruction and anastomosis, in cases such as the one we present, with multiple abdominal surgeries and whenever it is technically feasible, ureteral realignment may be a treatment option.

\section{REFERENCES}

1. Bryk DJ, Zhao LC. Guideline of guidelines: a review of urological trauma guidelines. BJU Int. 2016; 117:226-34.

2. Eswara JR, Raup VT, Potretzke AM, et al. Outcomes of Iatrogenic Genitourinary Injuries During Colorectal Surgery. Urology. 2015; 86:1228-33.

3. Morey AF, Brandes S, Dugi DD, et al. Urotrauma: AUA guideline. J Urol. 2014; 192:327-35.

4. Wang D, Wan SP. Retrograde Endoscopic Management of Completely Transected Ureter Discovered Postoperatively. J Endourol Case Rep. 2018; 4:84-6.

5. Liu C, Zhang X, Xue D, et al. Endoscopic realignment in the management of complete transected ureter. Int Urol Nephrol. 2014; 46:335-40.

\section{Correspondence}

Jorge Panach-Navarrete, MD (Corresponding Author) - jorge.panach@uv.es Av. Blasco Ibáñez, no 17, Valencia, CP 46010 (Spain)

Marcos Antonio Lloret-Durà, MD - marcosant.1loret@gmail.com

María Medina-González, MD - mariamedinagon@gmail.com

José María Martinez-Jabaloyas, MD PhD - marjabaloyas@gmail.com

Department of Urology. University Clinic Hospital of Valencia. Facultat de Medicina i Odontologia. Universitat de València, Valencia (Spain) 